\title{
The effect of boreal forest canopy to reflectance of snow covered terrain based on airborne imaging spectrometer observations
}

\section{Heinilä, Kirsikka}

2014-04

Heinilä , K, Salminen, M , Pulliainen , J, Cohen , J , Metsämäki , S \& Pellikka , P 2014 , ' The effect of boreal forest canopy to reflectance of snow covered terrain based on airborne imaging spectrometer observations ' , International Journal of Applied Earth Observation and Geoinformation, vol. 27 , no. Part A , pp. 31-41 . https://doi.org/10.1016/j.jag.2013.06.004

http://hdl.handle.net/10138/44806

https://doi.org/10.1016/j.jag.2013.06.004

publishedVersion

Downloaded from Helda, University of Helsinki institutional repository.

This is an electronic reprint of the original article.

This reprint may differ from the original in pagination and typographic detail.

Please cite the original version. 


\title{
The effect of boreal forest canopy to reflectance of snow covered terrain based on airborne imaging spectrometer observations
}

\author{
Kirsikka Heiniläa,c, Miia Salminen $^{\mathrm{a}, \mathrm{b}, *}$, Jouni Pulliainen ${ }^{\mathrm{b}}$, Juval Cohen ${ }^{\mathrm{b}}$, \\ Sari Metsämäki ${ }^{a}$, Petri Pellikkac \\ a Finnish Environment Institute, P.O. Box 140, 00251 Helsinki, Finland

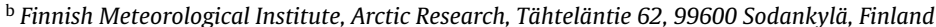

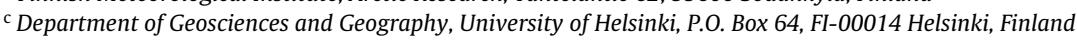

\section{A R T I C L E I N F O}

\section{Article history:}

Received 20 December 2012

Accepted 18 June 2013

\section{Keywords:}

Spectral reflectance

NDSI

NDVI

Boreal forest

Snow

AisaDUAL

\begin{abstract}
A B S T R A C T
Optical remote sensing methods for mapping of the seasonal snow cover are often obstructed by the masking effect of forest canopy. Therefore, optical algorithms tend to underestimate the amount of snow cover in forested regions. In this paper, we investigate the influence of boreal forest stand characteristics on the observed scene reflectance under full dry snow cover conditions by applying an advantageous experimental setup combining airborne hyperspectral imaging and LIDAR data sets from a test region in Sodankylä, northern Finland. This is particularly useful to the understanding of the composition of the mixed satellite scene reflectance behavior and it is relation to the natural ground targets' spectral signatures.

At first, we demonstrate the effects of varying forest stand characteristics, including Canopy Cover (CC), Tree Height $(\mathrm{TH})$ and the product of the these parameters referred to as CCXTH, on the reflectance measured by airborne imaging spectrometer AisaDUAL. Then, we analyze the effects of the presence of snow on forest canopy on the observed AisaDUAL data. The analysis of the effects of canopy was enabled by the high resolution LIDAR measurements which provide reference information on forest canopy characteristics. According to the results the change in Canopy Cover, as well as in CCXTH, is related to the observed change in reflectance, as well as to changes in such spectral indices as Normalized Difference Snow Index (NDSI) and Normalized Difference Vegetation Index (NDVI). Additionally, NDSI was found to vary extensively particularly in dense forests (CC $>85 \%)$, where the relative variation was over $100 \%$. This should be considered when applying NDSI-based snow mapping methods in the case of forested areas. One notable finding was that the relation between the forest characteristics and reflectance was nearly exponential, while with reflectance indices it was linear. Besides, the results show that NDSI was a more effective parameter in detecting snow on canopy (values deviated 0.3 on average) than NDVI (values deviated 0.3 on average) in all Canopy Cover classes. The difference in NDSI between these two cases, snow-covered and snow-free canopy, increased when the canopy coverage increased.
\end{abstract}

(C) 2013 Published by Elsevier B.V.

\section{Introduction}

The development of improved and accurate methods to describe satellite-based observations as a function of regionally varying scene (target) characteristics, i.e. forward modeling, requires extensive and reliable experimental datasets. The feasibility of geo/biophysical variable estimates retrieved from satellite-data is most of all dependent on how reliable is this forward modeling. Thus, e.g. in developing and improving methods for seasonal snow cover monitoring in boreal forests, high spatial and spectral resolution information on the investigated scene properties and their

\footnotetext{
* Corresponding author. Tel.: +358 400148 747; fax: +358 954902690

E-mail address: miia.salminen@environment.fi (M. Salminen).
}

temporal behavior are required. Above all, it is crucial to combine the employment of in situ data of the scene characteristics, coinciding near-range remote sensing reference observations (e.g. airborne, mast- or ground-based) and satellite observations. Using optical snow mapping instruments, such as the MODIS (Moderate Resolution Imaging Spectroradiometer) aboard Terra, specifically the forest disturbs the snow covered area detection as the trees prevent the visibility of snow-covered ground. In open areas with full snow cover the error in detecting snow from a satellite is usually very tolerable, typically less than $1 \%$, but in forested areas the error has been found to be much larger, even 76\% in Metsämäki et al. (2012).

Retrieval of fraction of snow covered area (FSC) using optical data is based on the high reflectance of snow in visible (VIS) and near-infrared (NIR) wavelengths compared to other natural 
targets (Wiscombe and Warren, 1980). Spectral unmixing methods for FSC mapping are presented e.g. by Painter et al. (2003) and Vikhamar and Solberg (2003a,b). Moreover, the algorithm of NASA/Goddard Space Flight Center estimates the FSC from Normalized Difference Snow Index (NDSI) using linear regression (Hall and Riggs, 2007; Riggs et al., 2006; Salomonson and Appel, 2004, 2006). A typical defect with these methods is their weaker performance over forested areas. The semi-empirical reflectance model-based method SCAmod for FSC mapping in boreal forest and tundra belt using optical data was proposed by Metsämäki et al.(2005).SCAmod originates from radiative transfer theory and describes the scenelevel reflectance as a mixture of three major constituents - opaque forest canopy, snow and snow-free ground, which are interconnected through forest canopy transmissivity and snow fraction. The method has proven to be feasible for global scale snow cover mapping and is particularly designed to give a good performance also for forested areas (Metsämäki et al., 2012). However, in SCAmod, the spatial and temporal variation in the utilized reflectance causes potential error in the satellite FSC retrieval when different constituents of modeled reflectance have standard constant values in the parametrization of SCAmod (Metsämäki et al., 2012; Niemi et al., 2012; Salminen et al., 2009). In order to quantify the magnitude of this error, high resolution measurements in controlled condition are required. The usability of satellite data can be improved (e.g. by better forward modeling) by applying more accurate snow-free ground, forest canopy and wet snow reflectances as model parameters (Metsämäki et al., 2012; Niemi et al., 2012; Salminen et al., 2009).

High resolution airborne optical measurements of snowcovered forests accompanied with LIDAR (Light Detection and Ranging) data-derived detailed forest canopy characteristics enable an advanced analysis of forest cover effects on space-borne observations, which is the key novelty of this investigation. The use of extensive data sets from Sodankylä test region, northern Finland, enables the development of optical snow mapping method, and their further validation and regional parameterization. Additionally, the mast-based spectral observations are particularly useful for determining the temporal behavior of forest scene reflectance (Niemi et al., 2012; Salminen et al., 2009). The effects of tree characteristics on the observed reflectance have been investigated earlier, while there is less information available on the spectral differences between various coniferous forest stands in snow-covered conditions (e.g. Betts and Ball, 1997; Ni and Woodcock, 2000; Rautiainen et al., 2004). The combined utilization of the airborne AisaDUAL (Airborne Imaging Spectrometer for Applications) hyperspectral data and LIDAR data with full dry snow cover enables the detailed examination of the effects of the forest stand properties, such as Canopy Cover (CC) and Tree Height (TH), to the observed scene reflectance. Moreover, the exploitation of the high spatial resolution airborne and ground based reflectances acquired under homogeneous dry snow cover conditions is beneficial for the modeling of the scene reflectance of forested terrain. Additionally, the airborne AISA and LIDAR data were utilized in the investigation of the effects of snow on canopy on scene reflectance in different types of forest. This is a further contribution to earlier work that indicates the significant influence of snow on canopy to boreal forest albedo (Kuusinen et al., 2012; Manninen and Stenberg, 2009; Niemi et al., 2012).

The scope of this research is the modeling of the effect of tree canopy on snow mapping in boreal forests. In the next step of the research the results will be used in the developing spectral un-mixing methods and reflectance model-based snow monitoring. Furthermore, the obtained full spectrum dataset facilitates the adaptation and development of snow mapping methods for current and future optical satellite sensors with different optical channels. To summarize, we apply scene-level observations from aerial
Table 1

The measurement conditions on 18 March 2010 when the canopy was snow-free and on 21 March 2010 when the canopy was snow-covered. The proportions are from the area monitored by mast-borne spectrometer analyzed from digital image.

\begin{tabular}{lll}
\hline & $\begin{array}{l}\text { 18 March 2010 } \\
\text { at 10:05 UTC }\end{array}$ & $\begin{array}{l}\text { 21 March 2010 } \\
\text { at 10:05 UTC }\end{array}$ \\
\hline Solar azimuth $\left({ }^{\circ}\right)$ & 175.5 & 175.7 \\
Solar elevation $\left({ }^{\circ}\right)$ & 21.7 & 22.9 \\
Snow depth $(\mathrm{cm})$ & 77 & 83 \\
$\quad$ Grain size $(\mathrm{mm})$ & 0.54 & 0.38 \\
$\quad$ Proportion of snow-free & 62.4 & 39.5 \\
$\quad$ canopy $(\%)$ & 3.8 & 11.9 \\
Proportion of directly & & \\
$\quad \begin{array}{l}\text { illuminated snow at ground } \\
\quad \text { and on canopy }(\%)\end{array}$ & 34.0 & 48.6 \\
$\quad$ Proportion of shadowed snow & & -7 \\
$\quad$ at ground and on canopy $(\%)$ & -6 & -5 \\
$\begin{array}{l}\text { Snow surface temperature }\left({ }^{\circ} \mathrm{C}\right) \\
\text { Air temperature }\left({ }^{\circ} \mathrm{C}\right)\end{array}$ & -4 & \\
\hline
\end{tabular}

campaigns to provide information on the behavior of optical spectral signatures relevant to the parameterization of forward models including canopy and ground components.

\section{Material and methods}

\subsection{Study area}

Sparse coniferous forest dominates the study area in the surroundings of the Arctic Research Center of the Finnish Meteorological Institute (FMI-ARC) in Sodankylä located in southern Lapland of Finland at $26.6^{\circ} \mathrm{E} 67.4^{\circ} \mathrm{N}$, about $100 \mathrm{~km}$ north of the Arctic Circle and $180 \mathrm{~m}$ above the sea level. This sub-arctic environment has long, cold continental winters, and it is characterized by seasonally snow covered forests and open wetlands. In general, snow layer in Lapland is rather homogenous until the spring melt-freeze metamorphosis starts. The Scots Pine (Pinus sylvestris) dominated forests are characteristic for the area as overall $92 \%$ of forests in southern Lapland are dominated by Scots Pines (fraction of pines $>75 \%$ ) (METLA, 2010).

\subsection{Airborne spectrometer data and processing}

The airborne hyperspectral data was acquired utilizing AisaDUAL, which combines two sensors. It provides very high spatial and spectral resolution data covering with VNIR sensor the spectral range of $400-970 \mathrm{~nm}$ and with SWIR sensor the range of $970-2500 \mathrm{~nm}$. The campaign was carried out in Sodankylä during full dry snow cover and ideal weather conditions, i.e. several minus degrees and cloudless sky, on 18 March and on 21 March 2010 (Table 1). On 18 March, the trees were snow-free and snow cover on ground was several days old, while on 21 March, the trees were snow-covered and the snow on trees and ground was newly fallen (Fig. 1). The hyperspectral data was acquired from helicopter at the altitude of $800 \mathrm{~m}$ producing a spatial resolution of $0.8 \mathrm{~m}$. The spectral resolution for the VNIR bands was $5 \mathrm{~nm}$ and for SWIR bands $6 \mathrm{~nm}$ totaling to 359 spectral bands. The image swath was $240 \mathrm{~m}$ and flight lines were several kilometers long. All measurements were carried out in direct illumination (i.e., clear sky: 0/8 to $2 / 8$ cloud cover). In both campaigns, Oxford Technical Solutions RT4000 GPS/INS was used, which enables high accuracy measurements with low drift rates. The instrument foreoptics unit was set to look at nadir $\left(0^{\circ}\right)$ direction and the field of view (FOV) was $17^{\circ}$. The data was radiometrically and geometrically corrected by using CaliGeo tool by SPECIM in the ENVI software. The AISA data was first filtered with mean filter using $12 \times 12$ window corresponding to pixel size of $10 \mathrm{~m}$ and then reprojected to the same grid with 


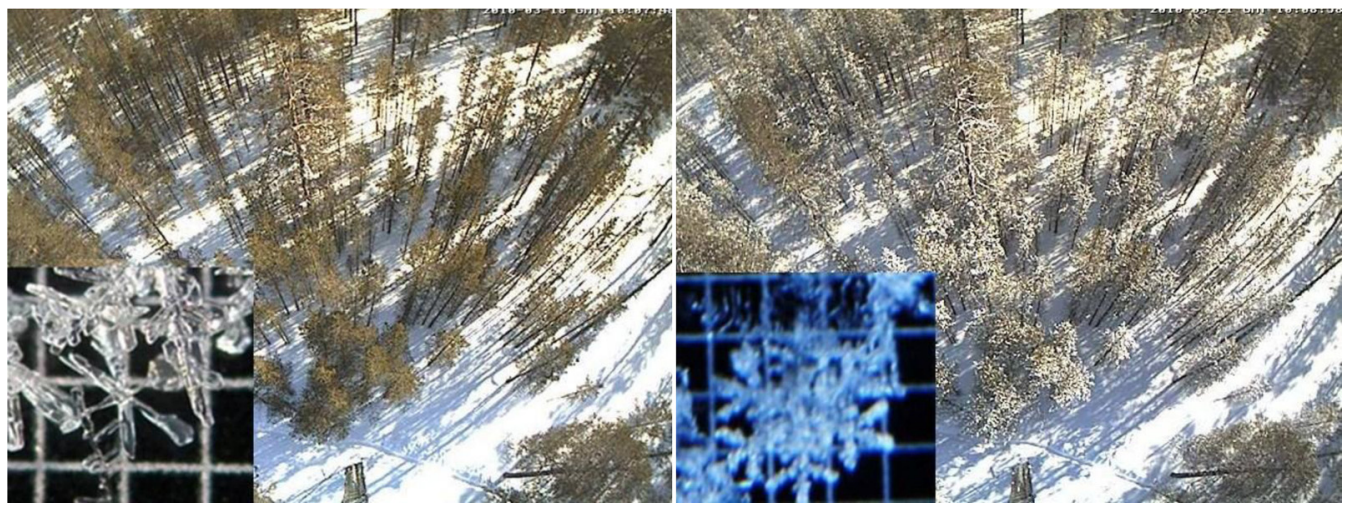

Fig. 1. The forest canopy and grain size on 18 March 2010 on the left and on 21 March 2010 on the right. Snow grain samples are on the 1-mm grid.

LIDAR data. Besides obtaining the correspondence with the LIDAR data, using the average value for $10 \mathrm{~m}$ grid reduces the error caused by irregular noise. The calibration of the absolute reflectance level of the AISA observations was performed by applying well calibrated ASD-spectrometer data from a 30-m high mast. The mast-borne system (calibrated by a white Spectralon panel) made reflectance measurements of a forest footprint concurrently with AISA image acquisitions. To get same level of reflectance for the mast-borne and AISA-observations of the forest footprint, calibration coefficients (for different VIS, NIR and SWIR wavelength ranges) were determined for the AISA data, see Section 2.4.

The AISA data was investigated using the bands and spectral indices relevant to MODIS snow mapping (Klein et al., 1998) (Table 2). The bands were extracted from the AISA spectra by using the band specific FWHM criterion (full width at half maximum) corresponding to MODIS bands (Table 2). AISA derived green ( $555 \mathrm{~nm}$ ) and near infrared $(858.5 \mathrm{~nm})$ bands, and NDSI and NDVI indices, were compared with the LIDAR based Canopy Cover (CC) and Tree Height (TH) maps. In addition, the AISA data was compared with the product of $\mathrm{CC}$ and $\mathrm{TH}$, referred to as $\mathrm{CCXTH}$. In order to find out the correspondence with the total forest canopy volume, $\mathrm{CCxTH}$ values were compared with the $25 \mathrm{~m}$ resolution volume of growing stock (VOL) data, which was calculated from Landsat images by the Finnish Forest Research Institute (METLA) (Tomppo et al., 2008). The comparison of these data sets is shown in Fig. 2 indicating a slightly non-linear relation between VOL and CCXTH values. The obtained second-degree fit is

$\mathrm{VOL}_{\text {modelled }}=-2.5 e-05 \times \mathrm{CCxTH}^{2}+0.081 \times \mathrm{CCxTH}+17$

Additionally, the comparison of the volume estimates (VOL) with the LIDAR data-derived Tree Height (TH) and Canopy Cover (CC) indicated that the product of these factors ( $\mathrm{CCxTH}$ ) has a higher correlation to total volume than when comparing these variables solely. Since the data on growing stock volume is not spatially as accurate as the LIDAR data-based reference information, it is reasonable to apply in the analyses here the CCXTH data instead of volume estimates retrieved from satellite data.

Table 2

Resampled reflectance bands and indices from AISA spectra.

\begin{tabular}{lcc}
\hline MODIS bands & Central wavelength $(\mathrm{nm})$ & Bandwidth $(\mathrm{nm})$ \\
\hline Band 1 & 645 & $620-670$ \\
Band 2 & 858.5 & $841-875$ \\
Band 4 & 555 & $545-565$ \\
Band 6 & 1640 & $1628-1652$ \\
& & \\
MODIS-based indices & & Formulation \\
\hline NDSI & & (Band 4 - Band 6)/(Band 4+ Band 6) \\
NDVI & (Band 2 - Band 1)/(Band 2 + Band 1) \\
\hline
\end{tabular}

The number of observations $(N)$ (i.e. the amount of $10 \mathrm{~m}$ grid cells) was 50200 except in the investigation of the TH. When the effect of TH was analyzed, only observations where CC was 30-70\% and $\mathrm{TH}>1 \mathrm{~m}(N=19100)$ were included in order to reduce the correlation between $\mathrm{TH}$ and $\mathrm{CC}$ (Fig. 3.). When studying the relation between the CC and indices, a linear model was fitted. An exponential model was used in describing the relation between the CC and AISA reflectances. For all the cases, the root mean squared error (RMSE) was calculated as follows:

RMSE $=\sqrt{\frac{1}{N} \sum\left(V_{\text {estim }}-V_{\text {AISA }}\right)^{2}}$

where $N$ is the number of observations, $V_{\text {estim }}$ is the value predicted by the fitted model (linear or exponential) and $V_{\mathrm{AISA}}$ is the reflectance or index derived from AISA data. Additionally, the interdependency between the NDSI and NDVI was investigated in the study area by analyzing the behavior of observations in NDSI-NDVI space. These indices are used in operational snow mapping, e.g. in NASA's binary snow algorithm a pixel is labeled as snow-covered if it has NDSI and NDVI values within a certain range taking into account the forest cover of the pixel (Klein et al., 1998). The effect of snow on trees on scene reflectance was analyzed by using NDSI

\section{LIDAR-based CCXTH vs Volume of growing stock}

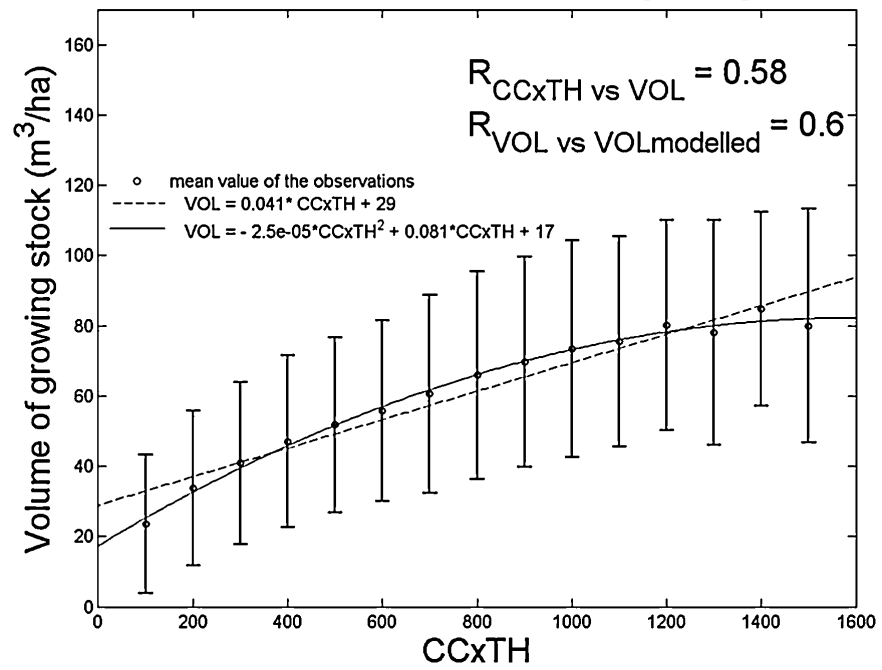

Figure 2. The mean values and the standard deviation of the volume of the growing stock (VOL) in different CCXTH classes (CCxTH-values are divided into 15 classes). The regression lines between $\mathrm{CCxTH}$ and the VOL data are also shown. Pearson's correlation coefficient $R$ is calculated between the CCxTH and the VOL data as well as between the modeled VOL values and VOL estimates determined from the coarser resolution satellite data. 


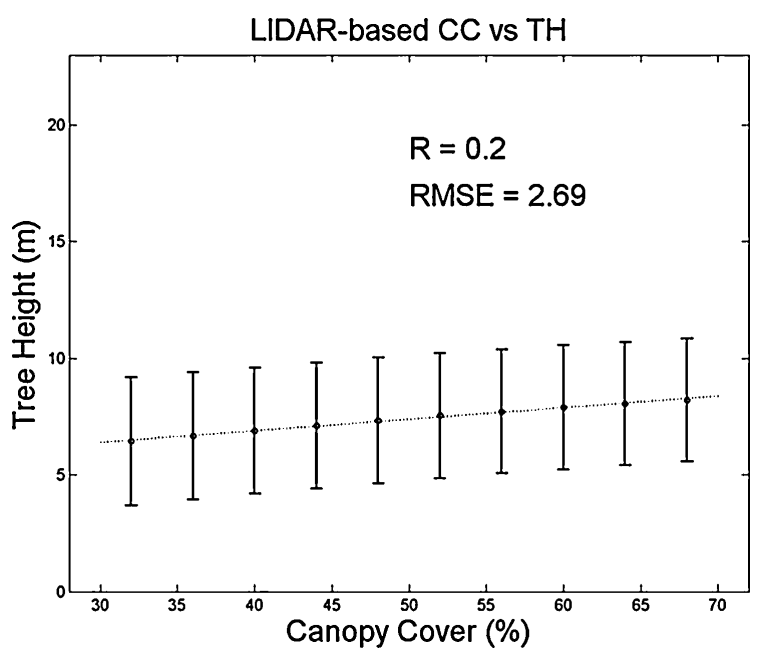

Fig. 3. The mean Tree Height $(\mathrm{TH})$ and standard deviation were calculated for Canopy Cover (CC) classes. A linear regression line between TH and CC is also shown. $R$ refers to Pearson's correlation coefficient and RMSE to Eq. (2).

and NDVI indices. They were employed as these indices are less sensitive to (small) differences in illumination geometry than band reflectances. AISA imaging spectrometer was set to look at nadir, which minimizes the effect of solar azimuth. The effect of solar elevation could be expected to be low due to the fact that it varied maximum 1 degree between the measurements from two days. Additionally, the relative difference $d_{\mathrm{r}}$ between the indices from two different days was calculated as follows:

$d_{\mathrm{r}}=\frac{V_{\mathrm{sf}}-V_{\mathrm{sc}}}{\left(V_{\mathrm{sf}}+V_{\mathrm{sc}}\right) / 2} \times 100 \%$

where $V_{\mathrm{sf}}$ is the AISA data-derived index value (NDSI or NDVI) for forest with snow-free canopy and $V_{\mathrm{sc}}$ is the index value for forest with snow-covered canopy. In the visualization of the mean and standard deviation for reflectance or index, the forest characteristics are presented in equal interval classes.

\subsection{LIDAR reference data processing}

The reference data covering the airborne spectrometer flight lines includes airborne high-resolution LIDAR measurements of forest canopy and terrain topography (Fig. 4). Based on LIDAR

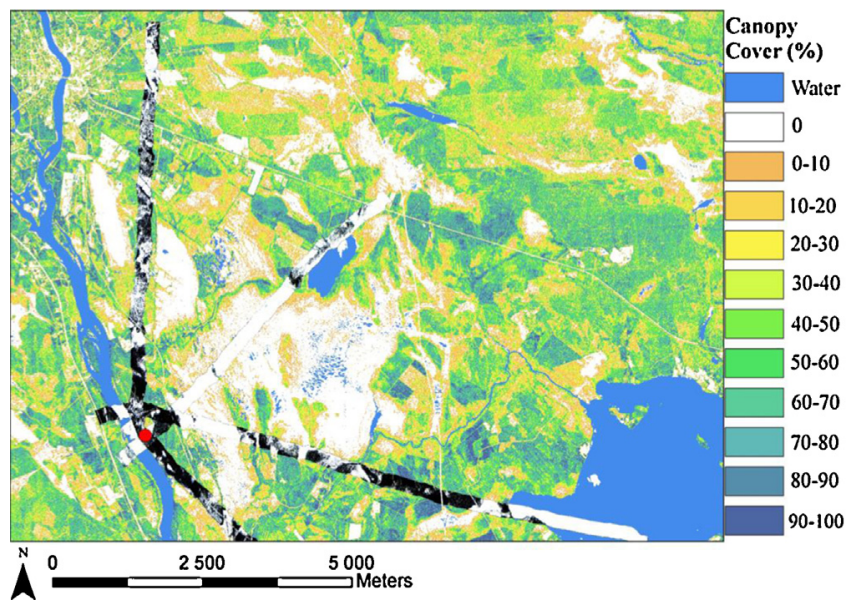

Fig. 4. Utilized AisaDUAL data from 18 March 2010 consists of four flight lines, same four flight lines was measured on 21 March 2010. In the background is forest Canopy Cover (CC) map derived from the LIDAR data. Red spot represents the location of mast-based spectrometer. measurements at snow-free conditions, a vegetation height map and a Canopy Cover map were derived for grid cells of $10 \mathrm{~m}$. First LIDAR point-cloud data was acquired for Sodankylä area from the National Land Survey of Finland. After, the point-clouds, with the point density of at least 0.5 points $/ \mathrm{m}^{2}$ (distance between each point approximately $1.4 \mathrm{~m}$ ), were transformed to a vegetation height raster image with a resolution of $2 \mathrm{~m}$. The vegetation height was retrieved by creating a digital surface model (DSM) from the LIDAR point cloud data, and subtracting the ground elevation from the DSM. The $10 \mathrm{~m}$ resolution Canopy Cover (CC) and Tree Height (TH) maps were both derived from the $2 \mathrm{~m}$ resolution vegetation height map. In the CC map, the value in percentage for each grid cell was retrieved by calculating the ratio between tree pixels (vegetation height over $1.5 \mathrm{~m}$ ) and the total number of $2 \mathrm{~m}$ pixels inside a $10 \mathrm{~m}$ grid cell. In the TH map, each pixel value in meters was either the mean value of the low vegetation pixels, or the mean value of the tree pixels if at least one tree pixel was inside the $10 \mathrm{~m}$ grid cell. The LIDAR measurements were acquired under leafless conditions, and therefore the CC map was suitable for AISA-based analysis from snow-covered forests. In the observed area, there were only sparsely distributed individual deciduous trees of birch (Betula ssp.) present.

\subsection{Mast-borne spectrometer data}

In addition to AISA observations, mast-borne spectrometer data was applied in the study, also for calibrating the AISA data. The ASD Field Spec Pro JR spectrometer, maintained by the FMI-ARC, measures radiance from a 30 -m-high mast. Spectral range of the instrument is $350-2500 \mathrm{~nm}$ with a spectral resolution about three $\mathrm{nm}$ for the band $350-1000 \mathrm{~nm}$ and of $10-12 \mathrm{~nm}$ for the band $1000-2500 \mathrm{~nm}$. The detector is at the end of an adjustable 6-mlong pole and is tilted $11^{\circ}$ from nadir (Sukuvaara et al., 2007). The sensor azimuth is $110^{\circ}$ and the FOV is $25^{\circ}$. The incoming radiation was determined by measuring the radiance from a white Spectralon panel at a particular wavelength $L_{I R}(\lambda)$ and by calibrating the measured radiance as follows:

$L_{\mathrm{IR}}(\lambda)=\frac{1}{R_{\mathrm{CAL}(\lambda)}} \times \frac{L_{\mathrm{CAL}}(\lambda)}{L_{\mathrm{REF}}(\lambda)} \times L_{\mathrm{Ref}}(\lambda)$

where $R_{\mathrm{CAL}}$ is the instrument background noise, $L_{\mathrm{REF}}$ is the radiance of the white Spectralon panel from the mast measured simultaneously with the new white Spectralon panel $\left(L_{\mathrm{CAL}}\right)$ in the laboratory, and $L_{\mathrm{Ref}}$ is the radiance of the white Spectralon panel of the mast at the time of the measurement.

The mast-borne spectrometer provides radiance data from two sites: (1) a forest and (2) a forest opening with tree shadows. For both of these $185 \mathrm{~m}^{2}$ sized areas an average instantaneous reflectance spectrum and simultaneously acquired digital images are obtained on a daily basis (Niemi et al., 2012; Salminen et al., 2009). The in situ (nadir) Canopy Cover in the observed forest stand is $40 \%$, though the canopy covered $48 \%$ of the spectrometer view due to the tilted imaging angle. The mast-borne reflectance data from snow covered forest (Fig. 5) from the field campaign dates, 18 March 2010 and 21 March 2010 was utilized. The reflectance data was used for illustrating the effect of solar position on scene reflectance with snow-free canopy and with snow-covered canopy.

\section{Results and discussion}

\subsection{The effect of tree characteristics on scene reflectance and indices}

Fig. 6 presents the mean reflectance or index values and standard deviation for each Canopy Cover (CC) equal interval class of $10 \%$-units ( $\pm 5 \%$ from the mean CC value). We found that $\mathrm{CC}$ 


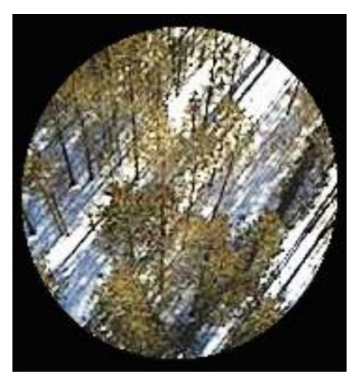

Fig. 5. The specific forest area of mast-borne ASD spectrometer measurements.

is nearly linearly related to both NDSI and NDVI, see Fig. 6c and $\mathrm{d}$. Also, the exponential relation between CC and the reflectance at wavelengths $555 \mathrm{~nm}$ and $858.5 \mathrm{~nm}$ is considerable (Fig. 6). The reflectances decreased, when the $\mathrm{CC}$ increased, due to the low reflectance of forest canopy compared to snow in the visible wavelengths (Fig. 6a and b). However, in this case the decrease of reflectance with increasing CC appears to obey an exponential function $a \times \exp (b \times C C)$, which is fitted to the Fig. $6 a$ and $b$. This appears to be in an agreement with modeling results, see e.g. Metsämäki
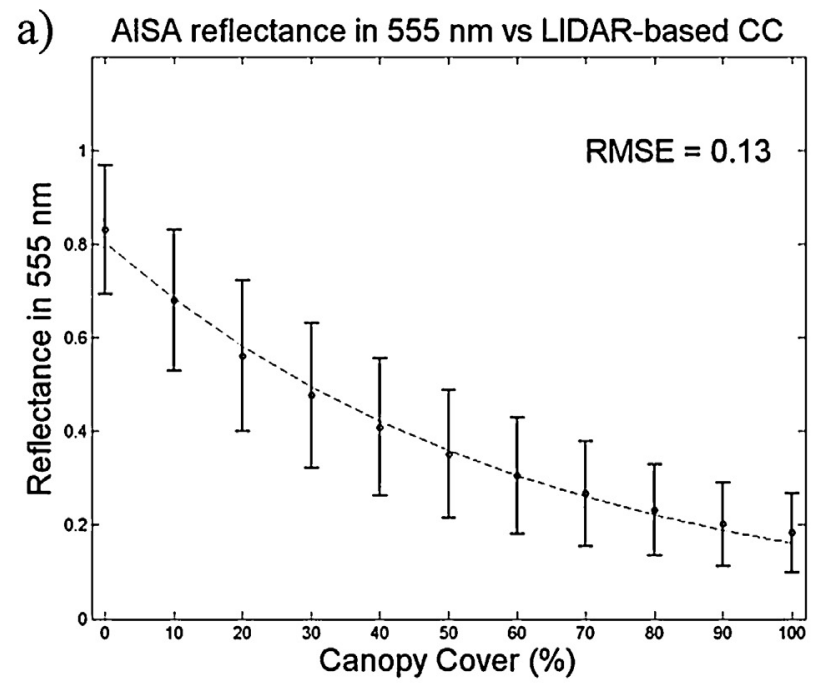

c) AISA-based NDSI vs LIDAR-based CC

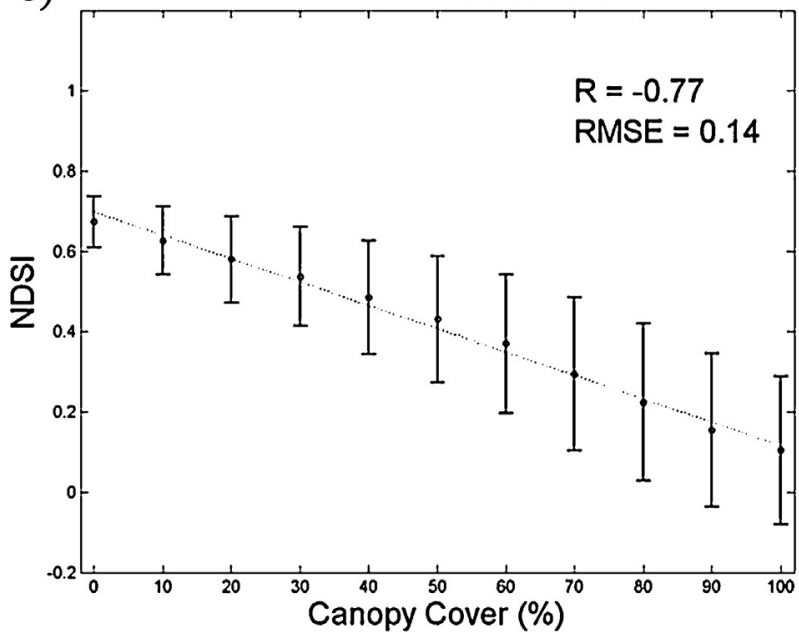

et al. (2005, 2012), Niemi et al. (2012), Salminen et al. (2009), Schlerf and Atzberger (2006). As CC has such a strong correlation with the scene reflectance, it is beneficial to include valid forest canopy transparency information (i.e. the proportion of the radiation that penetrates through the tree canopy layer) as input to satellite data retrieval algorithms. This is the case with the SCAmod that employs the forest canopy two-way transmissivity information. Ni and Woodcock (2000) investigated the effect of Canopy Cover on forest albedo and found that also the forest albedo varied dramatically as a function of Canopy Cover when the ground was snow covered. They also noticed that when CC > 70\% the presence of snow had only a minor effect on the observed albedo. This coincides well with our results in Fig. 6, where the reflectances did not vary considerably within the three highest CC classes (75-100\% CC).

Additionally, we found, that the standard deviation of the reflectances decreases with increasing CC, while NDVI and NDSI behaved oppositely gaining low variability in sparse forests (i.e. variation increases when CC gets higher). In dense forests (CC $>85 \%$ ), the relative variation of NDSI was over $100 \%$ while in sparse forests $(\mathrm{CC}<45 \%)$ it was less than $30 \%$. This agrees with the findings by Niemi et al. (2012), where NDSI and NDVI were less sensitive to variations in illumination geometry (including the

\section{b) AISA reflectance in $858.5 \mathrm{~nm}$ vs LIDAR-based CC}
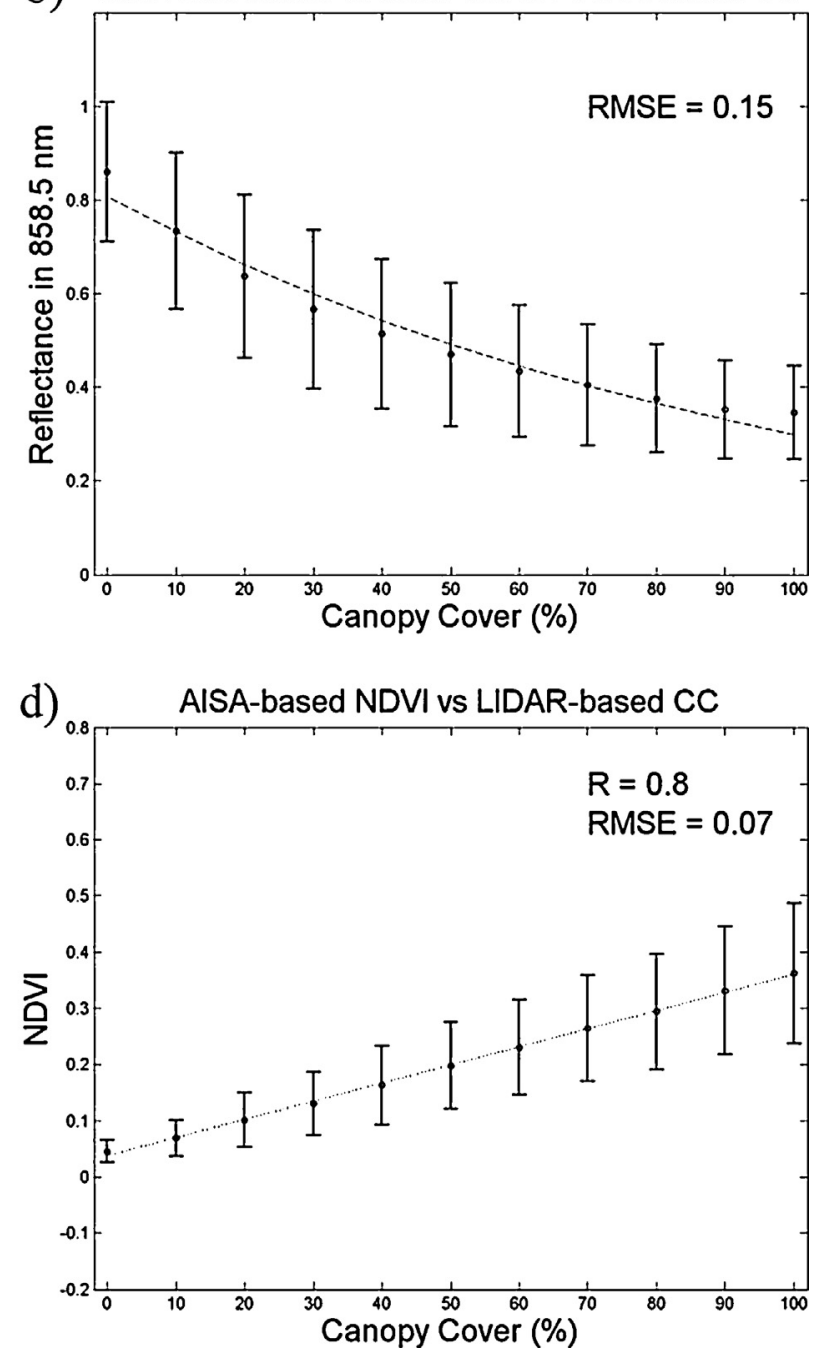

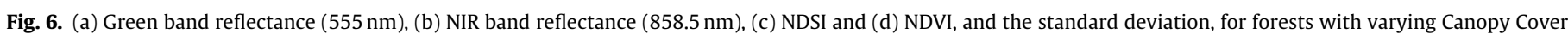

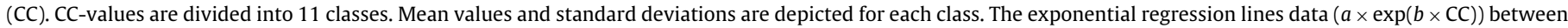

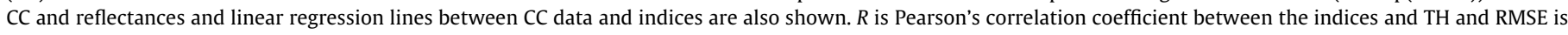
calculated using Eq. (2). 

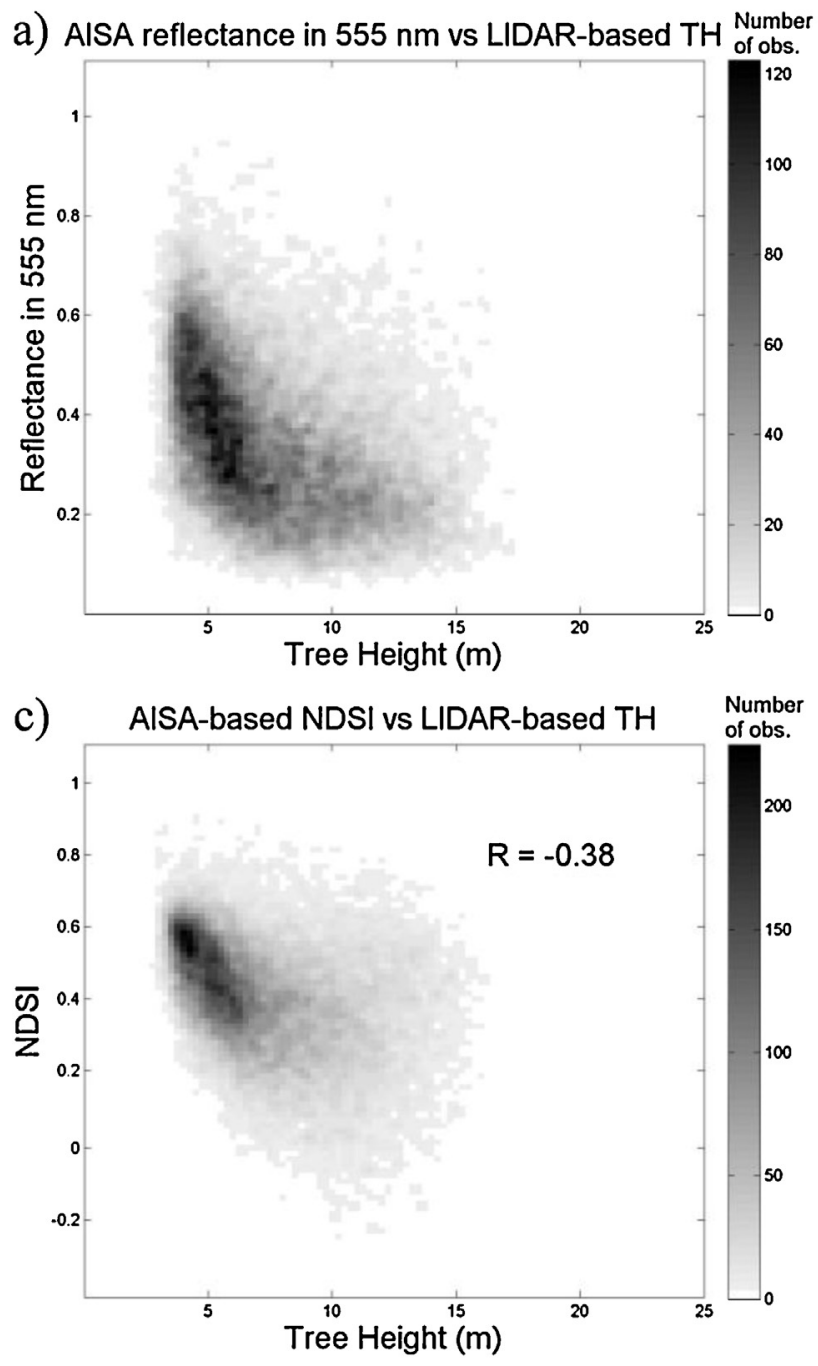
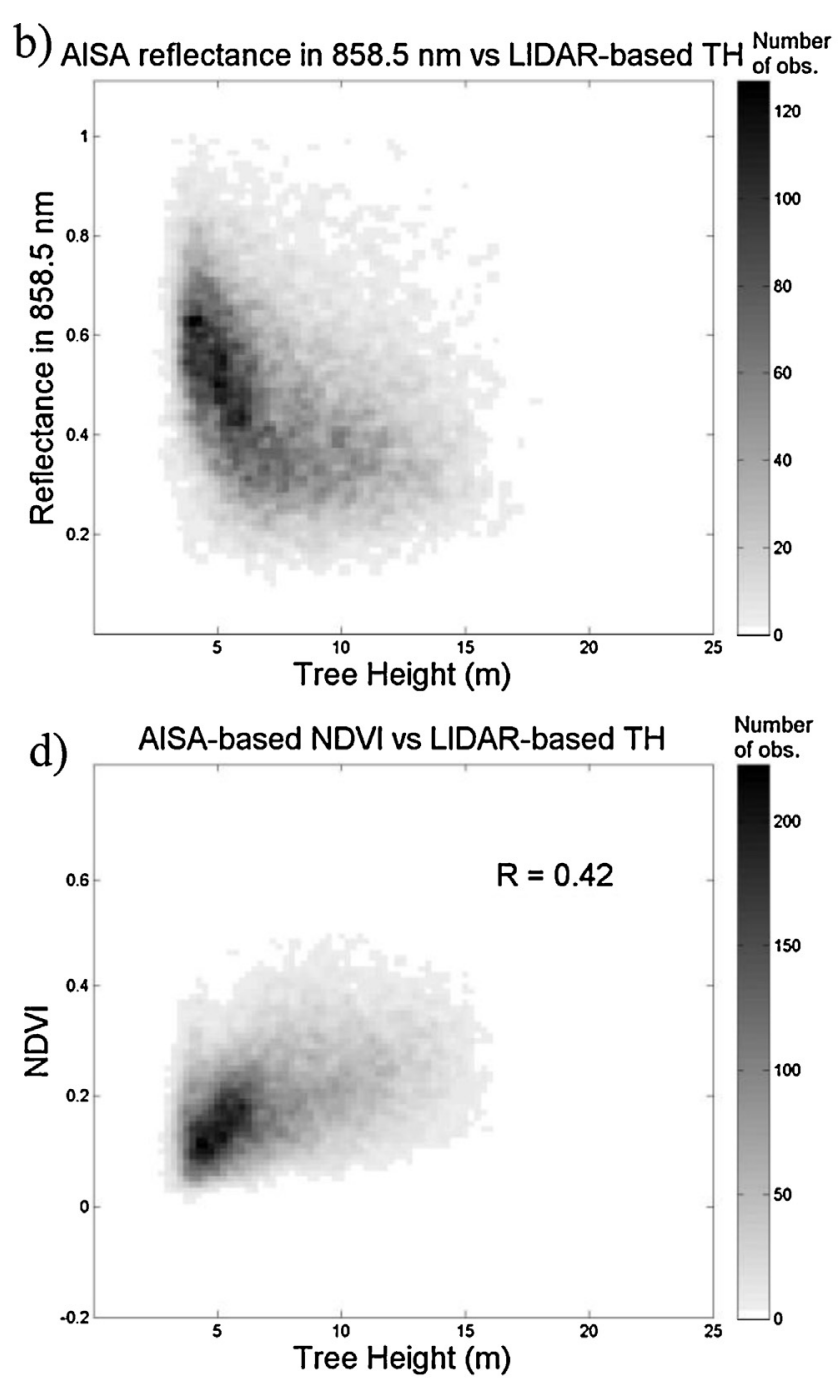

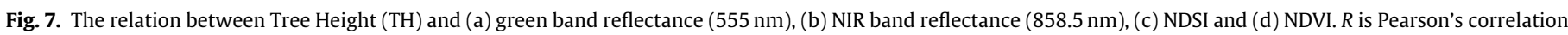
coefficient between the indices and $\mathrm{TH}$.

amount of shadows) in open areas. Moreover, illumination geometry induced large variation in the obtained reflectances. Results by Niemi et al. (2012) showed that it is beneficial to apply these indices for snow mapping in sparsely vegetated or open areas, based on the analysis of time-series of mast-based observations at single site (Sodankylä mast). This agrees well with the results obtained here using spatially distributed airborne observations. On the other hand, in forests the indices varied strongly, similar to our findings in dense forests. Cao and Liu (2006) have correspondingly found that the variation in NDSI (caused by e.g. solar zenith angle and instrument view angle) increased with decreasing snow covered area.

The Pearson's correlation coefficient $(R)$ between the TH and AISA data-derived reflectances or indices was not as strong as that in the case of CC (Fig. 7). When TH was around $5 \mathrm{~m}$, the reflectance varied in the range of $80 \%$. This might be explained by the variation in CC, though the lowest $(<30 \%)$ and the highest $(>70 \%)$ values of CC were excluded from the analysis. According to results, $\mathrm{TH}$ seems to correlate negatively with the reflectance values. Consistently with the CC, Fig. 7 illustrates that the response of reflectance to the increase of $\mathrm{TH}$ is merely nonlinear than linear. The reflectance is predominantly less than 0.2 in the band of $555 \mathrm{~nm}$ when the trees are higher than $15 \mathrm{~m}$ (Fig. 7a). The study of Heiskanen (2006) showed that the accuracy of the Tree Height estimates in the tundra-taiga transitions reduced around 10\% when multispectral nadir data was used together with the multi-angle data, when compared with the utilization of multispectral nadir data only. Similar improvements were found in the case of tree cover. When indices were plotted in the Canopy Cover and Tree Height space an interesting effect is observed for dense forests (Fig. 8): NDSI decreases for the highest and densest forests whereas NDVI increases with the increasing $\mathrm{TH}$ for all CC levels.

The behavior of reflectance and channel indices as a function of CCxTH is investigated in Fig. 9. As shown by Fig. 2, the product CCxTH has a slightly non-linear relation with the volume of growing stock. As the level of ground biomass is related to the volume of the growing stock (e.g. Boudewyn et al., 2007), CCxTH is also related to the level of biomass. Fig. 9 indicates that the reflectances observed at the $555 \mathrm{~nm}$ and $858.5 \mathrm{~nm}$ bands decrease non-linearly as a function of CCXTH. The sensitivity of NDSI and NDVI to the increase in $\mathrm{CCxTH}$ is also considerable with a negative nearly linear response in the case of NDSI and a positive response in the case of NDVI. Muukkonen and Heiskanen (2005) found that particularly green band reflectance was sensitive to tree biomass and, correspondingly to our CCxTH results, the shape of the correlation between the green band and biomass was more nonlinear than linear (Fig. 9a). NDVI has a low value in all cases with a low level of CCxTH. The increase of NDVI with increasing CCxTH is clear, but 

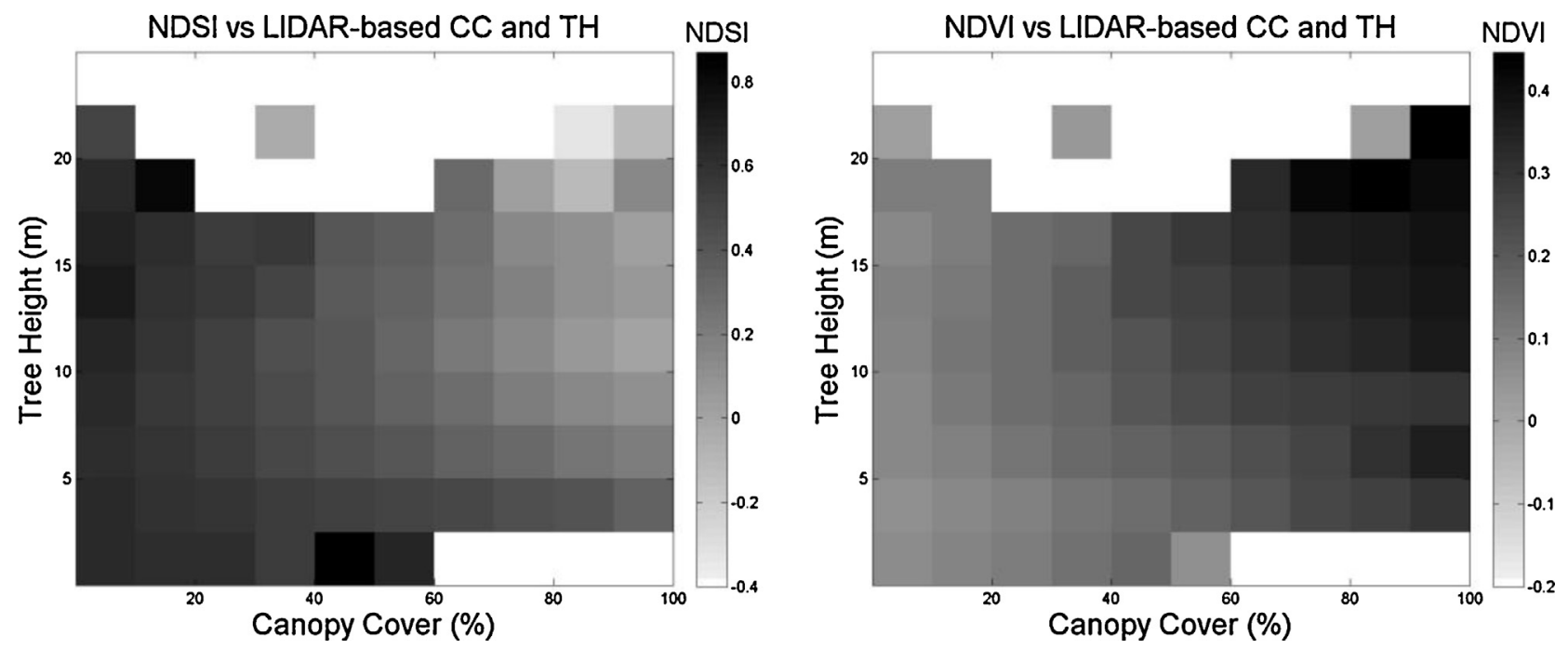

Fig. 8. NDSI versus Canopy Cover and Tree Height on the left and NDVI versus Canopy Cover and Tree Height on the right.
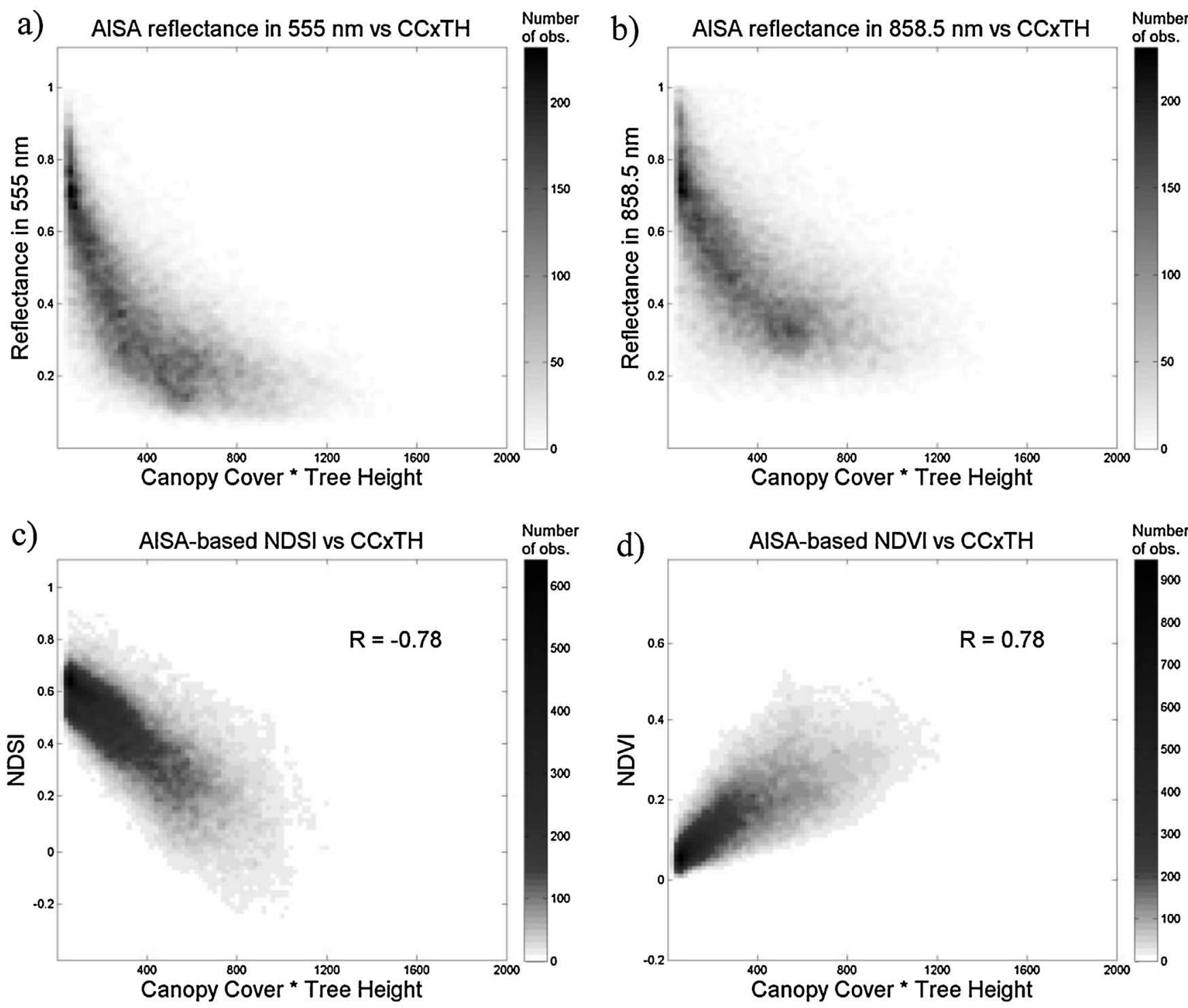

Fig. 9. The relation between the CCxTH and (a) green band reflectance $(555 \mathrm{~nm})$, (b) NIR band reflectance ( $858.5 \mathrm{~nm})$, (c) NDSI and (d) NDVI. $R$ is Pearson's correlation coefficient between the indices and $\mathrm{TH}$. 


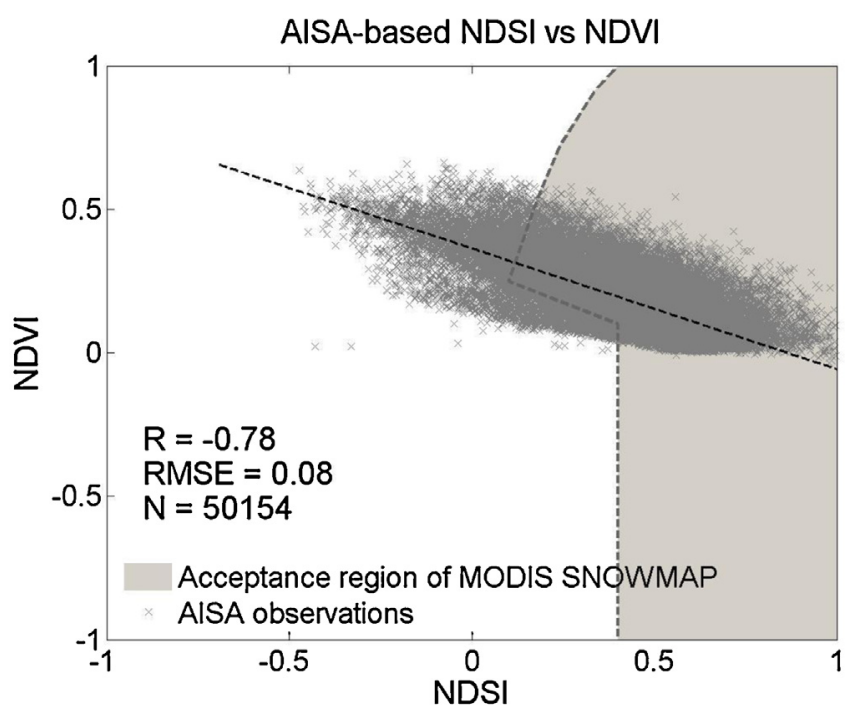

Fig. 10. The correlation between the NDSI and NDVI based on AISA observations with fully snow-covered open and forested areas (CC $=0-100 \%) . R$ is Pearson's correlation coefficient between NDSI and NDVI and RMSE is calculated with Eq. (2).

also the variation significantly increases (Fig. 9d). Rautiainen et al. (2004) found that reflectances increase with increasing crown volume, but in our case with CCXTH the correlation was negative. This is because the ground is covered by snow, and therefore, has high VIS and NIR reflectance dominating the signal at scene-level.

In addition, e.g. Fig. 9 illustrates that NDSI tends to get also negative values when CCXTH increases. The lowest observed NDSI was as low as -0.47 for forest area with CC of $76 \%$, CCXTH of 980 and NDVI of 0.63 . This coincides well with the results by Niemi et al. (2012) obtained by using mast-borne spectrometer data where the NDSI was found to obtained negative values in the forest with CC of $40 \%$. Similarly, Klein et al. (1998) modeled negative NDSI values in snow-covered forest stands, but the limit of NDSI to classify pixel as snow-covered in NASA's snow mapping method is set to minimum of 0.1 (Hall et al., 1998; Klein et al., 1998; Riggs et al., 2006). This is to avoid false snow interpretations in the case of snow-free conditions, as similar values for snow-free forests were obtained. In NASA's algorithm the threshold value for NDSI to detect snow cover depends on the NDVI value. In Fig. 10 is showed this region of MODIS binary snow algorithm which is set to detect snow cover.
Additionally, Fig. 10 demonstrates the behavior of NDSI against NDVI based on AISA observations on 18 March 2012 in fully snowcovered areas (snow-free canopy, snow depth about $80 \mathrm{~cm}$, see Table 1). NDSI and NDVI were found to be nearly linearly correlated. However, the spread in the observations is high, even though the measurement conditions were rather stabile during the data acquisition that was carried out within $1 \mathrm{~h}$. Thus, the variation is probably induced by forest characteristics. Most of the negative NDSI values were found in the forests where NDVI was $>0.3$. Xin et al. (2012) has described that the NDSI value determined using MODIS satellite images is prone to the changes in View Zenith Angle (VZA). They found that when VZA increases, NDSI decreases. In the case of AISA data, the effect of the variation of the VZA is negligible with the FOV only $17^{\circ}$ and allows us to investigate the relation between NDSI and NDVI without the disturbance of VZA. The NDSI-NDVI relation will be further investigated with AISA data acquired in snow-free conditions right after snow melt to discover the proper limits of NDSI to capture snow in boreal forests.

\subsection{The effect of snow on canopy on spectral behavior of reflectance and indices}

The applied AISA data set and the mast-based ASD spectrometer observation data set enabled the investigation the difference between the scenes with snow-free and snow-covered forest canopy. The presence of snow on canopy is a regular phenomenon in high latitudes and has been found to effect strongly on forest reflectance and albedo, see results e.g. by Manninen and Stenberg (2009) and Niemi et al. (2012).

In particular, the mast-based observations are used here to demonstrate the effect of illumination geometry on scene reflectance in both cases (Fig. 11). The results for snow-free and snow-covered canopies are analogously showing an increased level of reflectance for the case of backscatter. However, the effect of solar azimuth angle (with respect to instrument view angle) is stronger in the case of snow covered canopy for the infrared region (Fig. 11, right). Correspondingly, Kuusinen et al. (2012) found large variation in pine forest albedo, when the canopy was fully snow-covered. They deduced that changes in illumination conditions as well as the amount and properties of snow caused the variation. According the results from mast-borne spectra, the differences in the calibration or illumination geometry may cause variation to the reflectances from these two measurement days and only indices were employed in further investigations on canopy effect. The overall low values
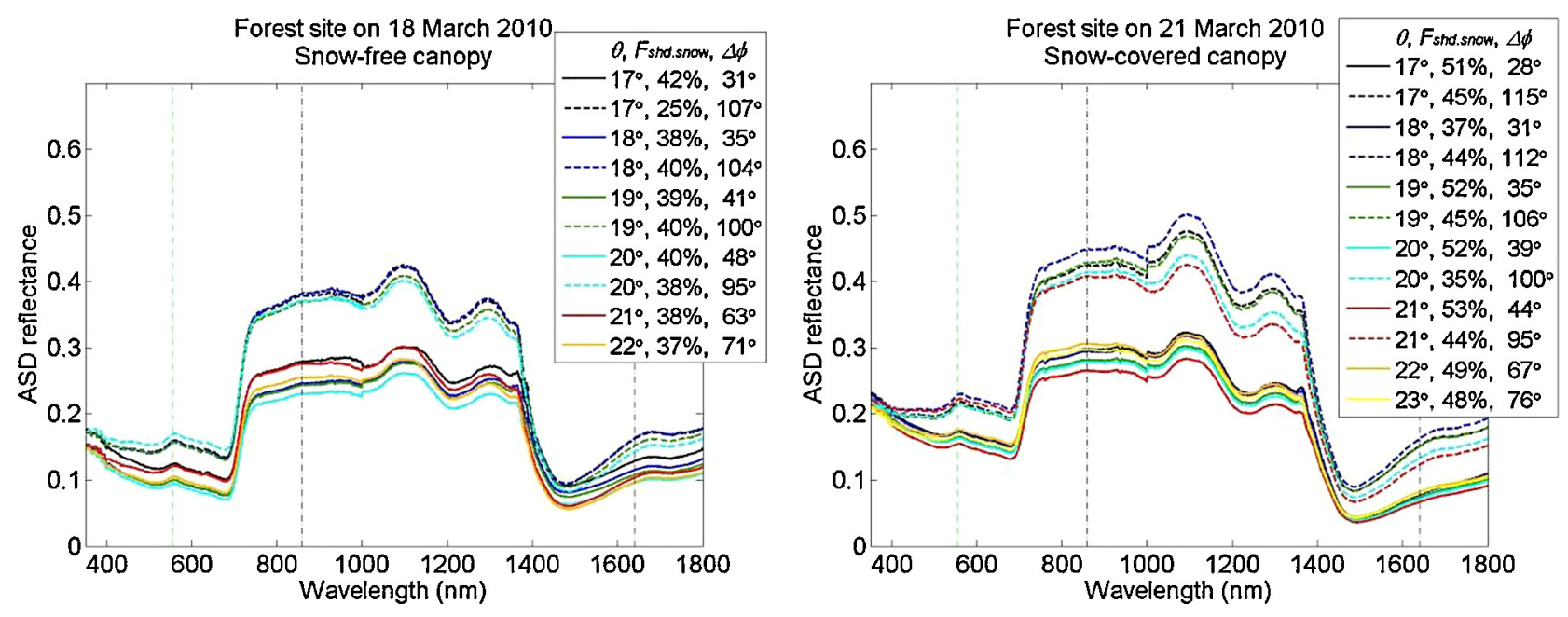

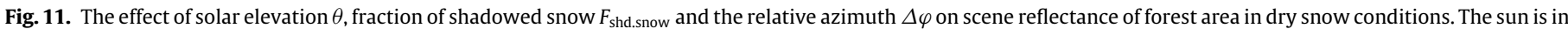

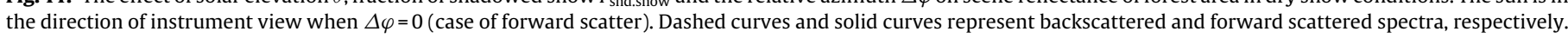
Left: Snow-free canopy. Right: Snow-covered canopy. 
a)

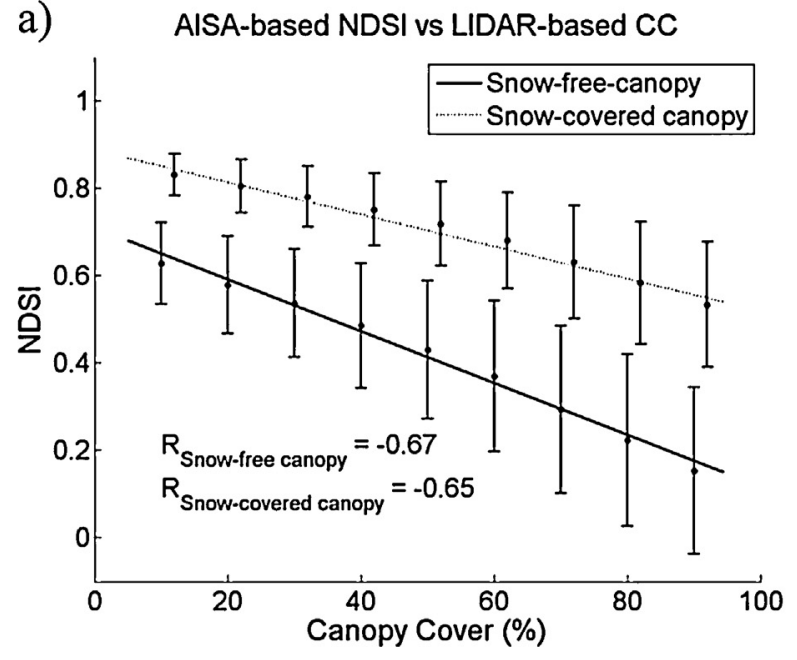

c)

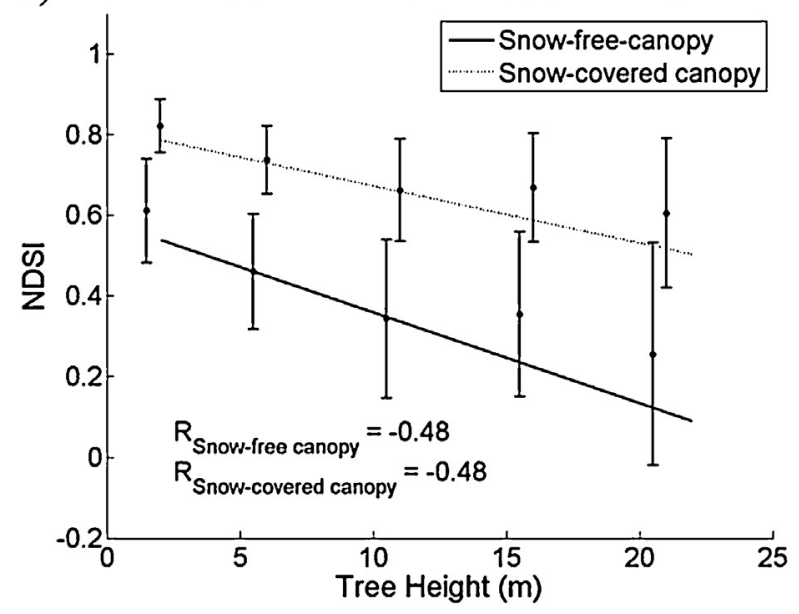

e) AISA-based NDSI vs LIDAR-based CCxTH

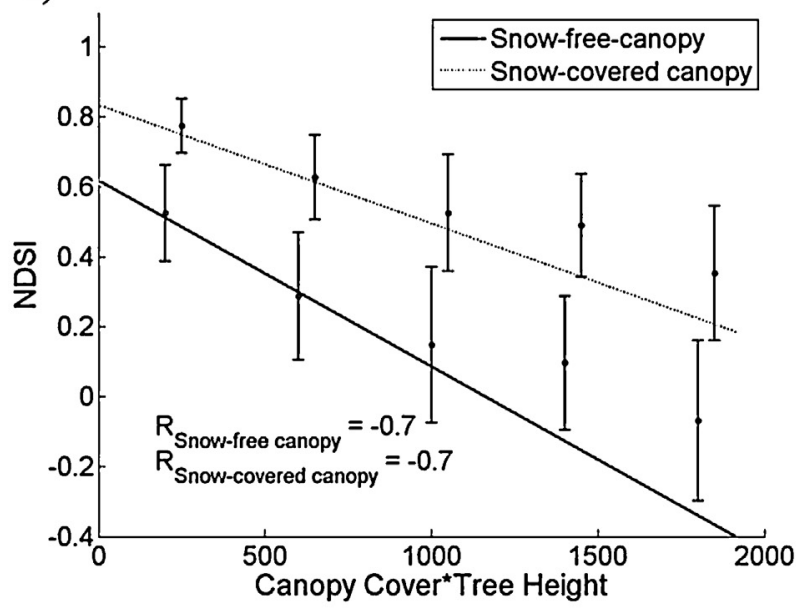

b)

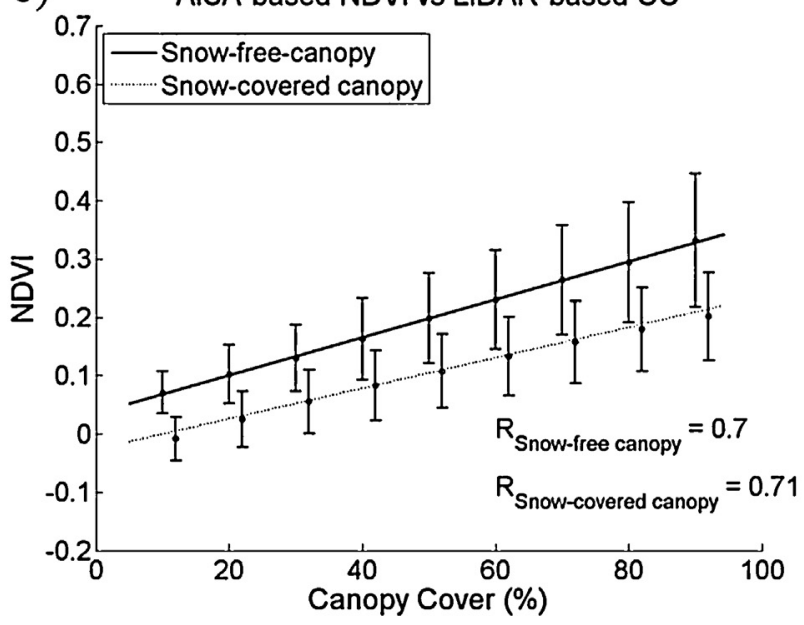

d)

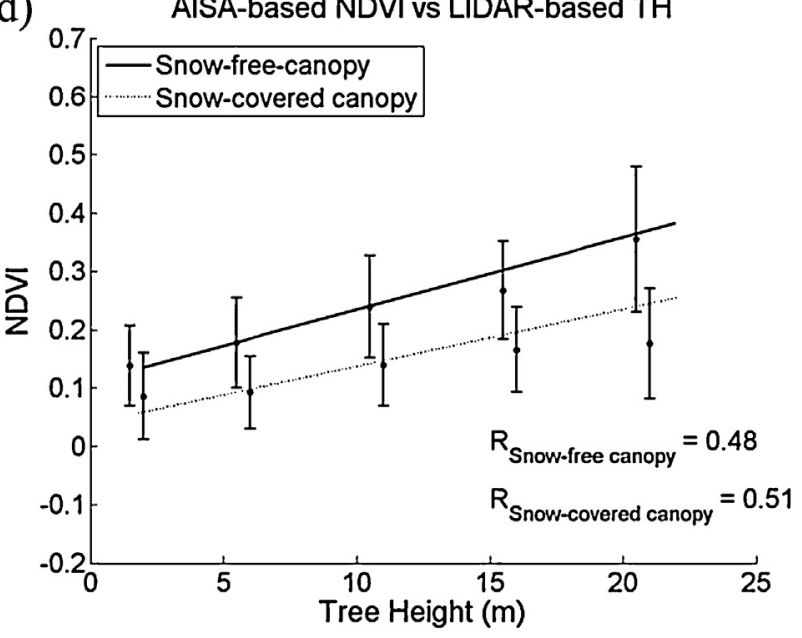

f)

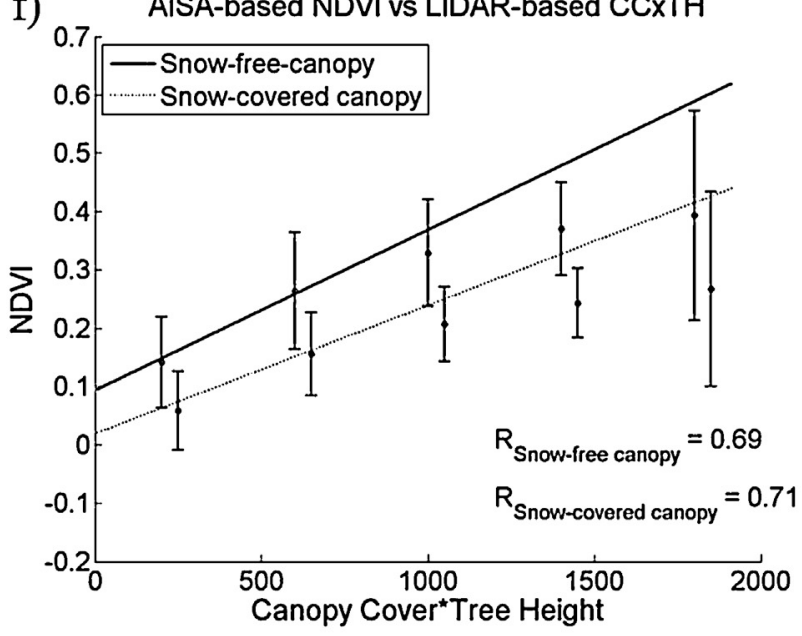

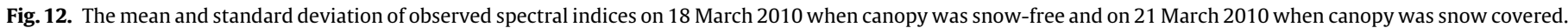

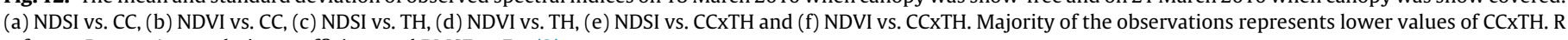
refers to Pearson's correlation coefficient and RMSE to Eq. (2).

especially in the visible wavelengths of the mast-borne spectra (Fig. 11, left) might be caused by the relatively high trees in the forest stand (TH around $12 \mathrm{~m}$ ), as the mean reflectance e.g. in $555 \mathrm{~nm}$ is 0.27 with std of 0.12 when $\mathrm{TH}$ is $12 \mathrm{~m}$ (see also Fig. 7a).

Fig. 12 depicts the AISA data-derived response of NDSI and NDVI to increase in CC, TH and CCxTH. For all Canopy Covers, snow-covered canopy introduces higher NDSI compared to snowfree canopy. The behavior of NDVI is the opposite. The strong effect of snow-covered canopy on forest albedo has been found in various investigations, see e.g. Manninen and Stenberg (2009) and Kuusinen et al. (2012). According to our results, the difference in indices between forest with snow-free and snow-covered canopy 
Table 3

The NDSI and NDVI for forest scene with snow-free canopy $V_{\text {sf }}$ and snow-covered canopy $V_{\mathrm{sc}}$ and their relative difference $d_{\mathrm{r}}$ for different forest categories.

\begin{tabular}{|c|c|c|c|c|c|c|c|c|c|c|c|c|}
\hline & \multicolumn{3}{|c|}{ Canopy Cover 10-30\% } & \multicolumn{3}{|c|}{ Canopy Cover 30-50\% } & \multicolumn{3}{|c|}{ Canopy Cover 50-70\% } & \multicolumn{3}{|c|}{ Canopy Cover 70-90\% } \\
\hline & $V_{\mathrm{sf}}$ & $V_{\mathrm{sc}}$ & $d_{\mathrm{r}}$ & $V_{\mathrm{sf}}$ & $V_{\mathrm{sc}}$ & $d_{\mathrm{r}}$ & $V_{\mathrm{sf}}$ & $V_{\mathrm{sc}}$ & $d_{\mathrm{r}}$ & $V_{\mathrm{sf}}$ & $V_{\mathrm{sc}}$ & $d_{\mathrm{r}}$ \\
\hline NDSI & 0.58 & 0.80 & $-32 \%$ & 0.48 & 0.75 & $-43 \%$ & 0.37 & 0.68 & $-60 \%$ & 0.23 & 0.59 & $-88 \%$ \\
\hline NDVI & 0.10 & 0.02 & $123 \%$ & 0.16 & 0.08 & $65 \%$ & 0.23 & 0.13 & $54 \%$ & 0.29 & 0.18 & $49 \%$ \\
\hline
\end{tabular}

increases when the CC or CCXTH increases. In addition, the variation in NDSI increases when CC increase, which can be seen from the behavior of standard deviation (Fig. 12). However, the snowcovered canopy reduces this variation. Table 3 presents a summary of the indices as well as relative difference (Eq. (3)) between the two cases. The difference between the snow covered and snow-free canopy is more than $30 \%$ in all CC classes in the case of both indices. The relative difference in NDVI increases when CC decreases. The relative difference of NDSI behaves oppositely i.e. increases when CC increases. This sensitivity of NDSI to the presence of snow on canopy in dense forests is explained by the higher change in total snow covered area (consisting of both snow on the ground and on the canopy). However, the lower impact of snow-covered canopy on NDSI especially in sparsely forested areas, where the proportion of snow-covered area is high (the visibility to snow layer is more extensive than in denser forests), might be partly explained by the smaller grain size of new snow. The increasing grain size as well as snow aging has been found to raise the NDSI value (Negi et al., 2010; Niemi et al., 2012). Niemi et al. (2012) found the strong impact of snow-covered canopy on NDSI and NDVI from mast-borne spectra. The CC of the area illuminated by mast-borne spectrometer is $40 \%$. In that case the relative difference was $156 \%$ for NDSI and $46 \%$ for NDVI. The higher impact on NDSI is explained by the differences in instrument viewing angle; AISA has a nadir view while the mast-borne spectrometer viewing angle is $11^{\circ}$. Xin et al. (2012) has found that in snow-covered forests NDSI decreased when VZA increased. They also discovered that with small VZA the effect was lower in sparse forest stands compared to dense forests. Overall, Fig. 12 depicts that NDSI values between snow-free and snowcovered canopy overlap less (deviated 0.31 on average) than in the case of NDVI (values deviated 0.10 on average) suggesting to utilize NDSI to detect the snow on canopy.

\section{Conclusions}

The behavior of remotely sensed spectral reflectance in selected bands, as well as the NDSI and NDVI, was found to be strongly affected by the spatial variations of forest canopy characteristics. An important finding was that the relation between the forest canopy properties and the observed reflectances shows a nonlinear curve, whereas with the investigated indices this relation is nearly linear. Canopy Cover (CC) as well as the product of CC and Tree Height (TH) $\mathrm{CCxTH}$ (corresponding with the volume of growing stock as well as with biomass), correlated rather well with the NDSI and NDVI (Pearson's correlation coefficient was 0.8 ). The obtained results demonstrate the feasibility of NDSI and NDVI for snow monitoring algorithms to detect snow cover underneath the forest canopy, but only for relatively sparse forests or in non-forested areas. In dense forest, the indices are less sensitive in detecting snow covered terrain, which is indicated by the increase of the variance of indices when CC increases, see Fig. $6 \mathrm{~b}$ and c. Especially with high NDVI $(>0.3)$, NDSI was found to show also negative values (even -0.5 , with NDVI =0.6). This large variation in the NDSI values depending on forest characteristics should be considered in NDSI-based snow mapping methods in case of forested areas.

When NDSI and NDVI of forests with full under-canopy snow cover were investigated with snow on canopy and with snow-free canopy, the results show NDVI values were almost similar (deviated 0.10 on average) for the scene with snow-covered canopy and snow-free canopy, whereas the NDSI values deviated more clearly ( 0.31 on average) between these two cases. The relative difference of NDSI between the two conditions increased with increasing CC.

These results could be used in the validation of the transmissivity data by analyzing their dependency on forest characteristics. This is important in order to reduce the obscuring effect of forest canopy over snow cover and to improve the accuracy of snow mapping algorithms. Moreover, the AisaDUAL data enables the improvement of the forward modeling using full spectral range, which is valuable as the terrain physical properties affect various spectral regions. Furthermore, the obtained full spectrum dataset facilitates the adaptation and development of snow mapping methods for current and future optical satellite sensors with different optical channels.

\section{Acknowledgements}

This work has been funded by the Airborne Imaging Spectroscopy Application and Research on Earth Sciences (AISARES) graduate school of the University of Helsinki. The work has been also supported by SPECIM (Spectral Imaging Ltd.) and CLIMWATER (Climate Change and Water Cycle: Effect to Water Resources and their Utilization in Finland) FICCA program project, funded by the Academy of Finland. Acquired AISA data was also supported by Bestcomp 97. Kft. and Meteo France. The work was also supported by the foundation Väisälän rahasto.

\section{References}

Betts, A.K., Ball, J.H., 1997. Albedo over the boreal forest. Journal of Geophysical Research: Atmospheres 102, 28901-28909.

Boudewyn, P.A., Song, X., Magnussen, S., Gillis, M.D., 2007. Model-based, Volumeto-Biomass Conversion for Forested and Vegetated Land in. Natural Resources Canada, Canada, Victoria, BC.

Cao, Y.-g., Liu, C., 2006. Normalized difference snow index simulation for snow-cove mapping in forest by geosail model. Chinese Geographical Science 16, 171-175.

Hall, D.K., Foster, J.L., Verbyla, D.L., Klein, A.G., Benson, C.S., 1998. Assessment of snow-cover mapping accuracy in a variety of vegetation-cover densities in Central Alaska. Remote Sensing of Environment 66, 129-137.

Hall, D.K., Riggs, G.A., 2007. Accuracy assessment of the MODIS snow products Hydrological Processes 21, 1534-1547.

Heiskanen, J., 2006. Tree cover and height estimation in the Fennoscandian tundra-taiga transition zone using multiangular MISR data. Remote Sensing of Environment 103, 97-114.

Klein, A.G., Hall, D.K., Riggs, G.A., 1998. Improving snow cover mapping in forests through the use of a canopy reflectance model. Hydrological Processes 12 1723-1744.

Kuusinen, N., Kolari, P., Levula, J., Porcar-Castell, A., Stenberg, P., Berninger, F., 2012. Seasonal variation in boreal pine forest albedo and effects of canopy snow on forest reflectance. Agricultural and Forest Meteorology 164, 53-60.

Manninen, T., Stenberg, P., 2009. Simulation of the effect of snow covered forest floor on the total forest albedo. Agricultural and Forest Meteorology 149, 303-319.

METLA, 2010. Finnish Statistical Yearbook of Forestry. Finnish Forest Research Institute, Vammala, Finland.

Metsämäki, S., Mattila, O.-P., Pulliainen, J., Niemi, K., Luojus, K., Böttcher, K., 2012 An optical reflectance model-based method for fractional snow cover mapping applicable to continental scale. Remote Sensing of Environment 123, 508-521.

Metsämäki, S.J., Anttila, S.T., Markus, H.J., Vepsäläinen, J.M., 2005. A feasible methoc for fractional snow cover mapping in boreal zone based on a reflectance model. Remote Sensing of Environment 95, 77-95.

Muukkonen, P., Heiskanen, J., 2005. Estimating biomass for boreal forests using ASTER satellite data combined with standwise forest inventory data. Remote Sensing of Environment 99, 434-447. 
Negi, H.S., Singh, S.K., Kulkarni, A.V., Semwal, B.S., 2010. Field-based spectral reflectance measurements of seasonal snow cover in the Indian Himalaya. International Journal of Remote Sensing 31, 2393-2417.

Ni, W., Woodcock, C.E., 2000. Effect of canopy structure and the presence of snow on the albedo of boreal conifer forests. Journal of Geophysical ResearchAtmospheres 105, 11879-11888.

Niemi, K., Metsämäki, S., Pulliainen, J., Suokanerva, H., Böttcher, K., Leppäranta, M. Pellikka, P., 2012. The behaviour of mast-borne spectra in a snow-covered boreal forest. Remote Sensing of Environment 124, 551-563.

Painter, T.H., Dozier, J., Roberts, D.A., Davis, R.E., Green, R.O., 2003. Retrieval of subpixel snow-covered area and grain size from imaging spectrometer data. Remote Sensing of Environment 85, 64-77.

Rautiainen, M., Stenberg, P., Nilson, T., Kuusk, A., 2004. The effect of crown shape on the reflectance of coniferous stands. Remote Sensing of Environment 89, 41-52.

Riggs, G.A., Hall, D.K., Salomonson, V.V., 2006. MODIS Snow Product User Guide to Collection 5. http://modis-snow-ice.gsfc.nasa.gov/uploads/sug_c5.pdf

Salminen, M., Pulliainen, J., Metsämäki, S., Kontu, A., Suokanerva, H., 2009. The behaviour of snow and snow-free surface reflectance in boreal forests: implications to the performance of snow covered area monitoring. Remote Sensing of Environment 113, 907-918.

Salomonson, V.V., Appel, I., 2004. Estimating fractional snow cover from MODIS using the normalized difference snow index. Remote Sensing of Environment 89, 351-360.
Salomonson, V.V., Appel, I., 2006. Development of the Aqua MODIS NDSI fractional snow cover algorithm and validation results. IEEE Transactions on Geoscience and Remote Sensing 44, 1747-1756.

Schlerf, M., Atzberger, C., 2006. Inversion of a forest reflectance model to estimate structural canopy variables from hyperspectral remote sensing data. Remote Sensing of Environment 100, 281-294.

Sukuvaara, T, Kyrö, E., Suokanerva, H. Heikkinen, P. Suomalainen, J, 2007. Reflectance spectroradiometer measurement system in 30 meter mast for validating satellite images. In: Proceedings of the IEEE 2007 International Geoscience and Remote Sensing Symposium (IGARSS), Barcelona Spain, pp. 2885-2889.

Tomppo, E., Haakana, M., Katila, M., Peräsaari, J., 2008. Multi-source National Forest Inventory - Methods and Applications. Springer, New York.

Vikhamar, D., Solberg, R., 2003a. Snow-cover mapping in forests by constraine linear spectral unmixing of MODIS data. Remote Sensing of Environment 88, 309-323.

Vikhamar, D., Solberg, R., 2003b. Subpixel mapping of snow cover in forests by optica remote sensing. Remote Sensing of Environment 84, 69-82.

Wiscombe, W.J., Warren, S.G., 1980. A model for the spectral albedo of snow. I: pure snow. Journal of the Atmospheric Sciences 37, 2712-2733.

Xin, Q.C., Woodcock, C.E., Liu, J.C., Tan, B., Melloh, R.A., Davis, R.E., 2012. View angle effects on MODIS snow mapping in forests. Remote Sensing of Environment 118, 50-59. 